\title{
OS DESAFIOS JURIDICOS DA REDE MUNDIAL DE COMPUTADORES NO BRASIL
}

\author{
Adriana Baker Goveia Araujo, Ana Augusta Rodrigues Westin Ebaid \\ Universidade do Oeste Paulista - UNOESTE, curso de Direito, Presidente Prudente, SP. E-mail: \\ adrianabgaraujo@gmail.com
}

\section{RESUMO}

O ordenamento jurídico deve acompanhar o progresso da sociedade, regrando o ambiente virtual, o qual possui, ainda, muitas ambiguidades sobre sua aplicabilidade. Destarte, este estudo pretende abarcar os desafios jurídicos que a rede mundial de computadores (internet) enfrenta no Brasil, apresentando tudo o que existe no ordenamento jurídico brasileiro sobre o tema, com interpretações e sugestões, realizando uma ligação entre o direito e a internet. $O$ artigo foi embasado em levantamentos bibliográficos, leituras de leis e artigos eletrônicos. Os dados foram examinados com a aplicação do método hipotético dedutivo, isto é, as informações coletadas, foram analisadas partindo do geral para o particular. $O$ trabalho direciona-se a realizar um estudo, vislumbrando tanto os aspectos penais quanto os cíveis, com o intuito de apresentar algumas soluções quando surgirem conflitos de normas jurídicas e circunstâncias que nunca foram arrazoadas na rede mundial de computadores.

Palavras-chave: Rede; Internet; Lei; Brasil.

\section{THE LEGAL CHALLENGES OF THE WORLD COMPUTER NETWORK IN BRAZIL}

\section{ABSTRACT}

The legal system must accompany the progress of society, ruling the virtual environment, which still has many ambiguities about its applicability. Thus, this study intends to cover the legal challenges facing the Internet in Brazil, presenting everything that exists in the Brazilian legal system on the subject, with interpretations and suggestions, making a connection between the law and the internet. The article was based on bibliographical surveys, readings of laws and electronic articles. The data were examined with the application of the hypothetical deductive method, that is, the information collected, were analyzed starting from the general to the particular. The work is directed to conduct a study, looking at both criminal and civil aspects, with the intention of presenting some solutions when conflicts of legal norms arise and circumstances that have never been reasoned in the world-wide computer network.

Keywords: Network; Internet; Law; Brazil.

\section{INTRODUÇÃO}

O conhecimento obtido pelo ser humano contíguo com a globalização conduziu a evolução tecnológica, a qual permeia a convivência dos indivíduos na era atual. Um momento em que os mecanismos eletrônicos são utilizados amplamente, para variadas finalidades, sejam transações comerciais, pesquisas (escolares/universitárias), aquisição de informações, comunicação, dentre outros escopos; inclusive para a prática de modalidades ilícitas.

Todavia, o Brasil acompanhou essa evolução tecnológica em diversos setores, como o industrial, educacional e jurídico, cujos procedimentos são realizados por meio eletrônico, podendo ser acessados por qualquer computador que esteja conectado com a rede (internet). Contribuindo, desta forma, para a celeridade do ambiente forense, algo garantido pela constituição federal, em seu artigo 5ㅇ, inciso LXXVIII; bem como a economia de papéis, 
colaborando com o meio-ambiente, conforme o artigo 225 do mesmo dispositivo. É sabido, portanto, baseando-se nos fatos existentes, que a internet atingiu uma admirável amplitude na sociedade, devendo ser vigiada e regrada por leis e princípios.

Portanto, o objetivo do presente artigo é realizar um estudo jurídico sobre as atuais Leis que regulam o uso da internet no Brasil, envolvendo qualquer circunstância que nela possa ocorrer, desde o seu âmbito penal até a sua esfera cível, com o intuito de propor algumas soluções para futuros conflitos de normas jurídicas e circunstâncias que nunca foram arrazoadas na rede mundial de computadores.

\section{METODOLOGIA}

O presente trabalho desenvolve-se através de bibliografias e artigos eletrônicos, realizando-se um estudo pelo método hipotético-dedutivo e contenda dialética. Onde ocorrerá uma verificação das Leis existentes no ordenamento jurídico brasileiro sobre a temática abordada, bem como a explanação de situações que incidem e interferem no cotidiano dos usuários da rede mundial de computadores.

\section{RESULTADOS}

Após a realização de um estudo sobre o ordenamento jurídico brasileiro, o qual submergiu a rede mundial de computadores, foi demonstrado por meio do objeto de estudo a dificuldade de se tipificar crimes que incidem no mundo virtual em decorrência de sua amplitude; além da falta de aptidão dos Legisladores no referido tema, o que acarreta um anacronismo jurídico no mundo eletrônico.

\section{DISCUSSÃO}

Apesar do ordenamento jurídico brasileiro ser formado por um intenso material, pouco se tem explanado no código de leis deste país sobre a temática internet, sendo imprescindível a realização de uma pesquisa, para averiguação de como se encontra atualmente a rede mundial de computadores no dispositivo jurídico, de que forma ela está disposta e como influencia no cotidiano dos usuários e da sociedade; se existem impedimentos, como atos ilícitos que podem ser praticados na internet, bem como se há um regulamento para termos muito comuns utilizados no mundo virtual, como por exemplo, disposições sobre um provedor (empresa que fornece a internet). Portanto, se faz necessária à realização de uma ponderação detalhada sobre o âmbito do "direito e dever digital", com o intuito de verificar as possibilidades corriqueiras que o mundo virtual pode proporcionar a coletividade; além de uma contribuição para a sociedade, onde os usuários poderão discernir com perceptibilidade todos os "direitos e deveres" que permeiam este ambiente.

Todavia, a rede mundial de computadores, mais popularmente conhecida como internet, que inicialmente envolvia somente o meio acadêmico e empresarial, passou a abranger a todas as conjunturas que fazem parte de nosso mundo atual, com sistemas integrados e acessíveis; onde um bom exemplo desta extensão é a sua presença nas escolas, no trabalho, no âmbito residencial, nos meios de transporte e até mesmo na esfera judicial, pois se tornou parte do nosso cotidiano. Sendo que até mesmo os processos judiciais já são informatizados, ou seja, tornaram-se eletrônicos, funcionando através de um sistema integrado na rede mundial de computadores, o qual labora atualmente de forma dinâmica e hábil, tornando célere e segura a tramitação e comunicação, bem como a transmissão das peças processuais. Ampliando-se de tal forma, que atualmente atinge uma escala mundial em decorrência da globalização, como dispõe Liliana Minardi Paesani (2014, p. 01): 
A sociedade caminha para a globalização como consequência da revolução tecnológica e da explosão da comunicação que universaliza hábitos, culturas e formas de produção e consumo. Os meios de comunicação de massa, potenciados por novas tecnologias, rompem fronteiras culturais, políticas, religiosas e econômicas.

É sabido que a globalização trouxe consigo uma comodidade para os indivíduos, além de promover a integração e a aproximação entre os países, organizações e pessoas; benfeitorias como estas que possuem um custo mínimo e aditamentos infinitos no que tange principalmente a comunicação, transporte, circulação de bens, serviços, capital e conhecimento, facilitando a criação de instituições que possam atingir um nível internacional (MARTINS, 2014).

Portanto, é apropriado ressaltar que a internet passou a ser habitual e corriqueira para a existência diária dos indivíduos, criando inevitavelmente direitos e obrigações, fazendo surgir relações jurídicas, bem como plausíveis crimes concretizados através da rede mundial de computadores, como aponta André Francez (2013, p.11):

Em vista disso, a avassaladora e dinâmica revolução tecnológica, principalmente no campo da internet e suas inúmeras facetas e formas de utilização, torna difícil ao legislador a tarefa de acompanhar e antever seus inúmeros matizes do ponto de vista fático-jurídico-criminal, eventualmente passíveis de criminalização. Muitas vezes será preciso esperar a conduta acontecer para, posteriormente, criminalizá-la, a fim de não tisnar o sagrado e intangível princípio da reserva legal. É certo que a internet pode ser utilizada como meio de consecução de crimes já previamente tipificados no Código Penal. Um exemplo paradigmático e clássico de utilização da internet como meio eficaz na consecução de crime já tipificado é o delito de estelionato, insculpido no art. 171 do Código Penal.

Deste modo, o uso da rede de computadores, ocasiona a relação da internet com determinados direitos que podem ser encontrados em nosso ordenamento jurídico, como os constitucionais, os de comércio, marketing, publicidade, entre outros. Tornando-se uma matéria comum nas jornadas diárias da sociedade a um nível mundial, sendo evidente a real urgência e necessidade da discussão e aprimoramento da disciplina Direito e Internet, um tema tão vago e superficial juridicamente no Brasil. Salienta Guilherme Magalhães Martins (2014, p. 14):

O desenvolvimento da computação em uma rede aberta, ou em um conjunto de redes que atravessam todo o planeta, como a Internet, traz novos desafios aos operadores do direito. Inicialmente, o computador se destinava apenas a automatizar e expandir as práticas informacionais já existentes, tanto no setor público como na iniciativa privada. No estágio atual, as redes deram aos particulares o acesso a poderes na área da computação que anteriormente eram reservados apenas aos governos. Surgem novos interesses e situações jurídicas, tanto patrimoniais quanto existenciais, insuscetíveis de serem tratados com base nos paradigmas do passado. O grande desafio é conciliar a rapidez da evolução tecnológica com a liberdade de expressão dos usuários, marcante no desenvolvimento da Internet. 
Com relação aos direitos fundamentais, que são direitos básicos que todos os cidadãos carecem, eles também se localizam neste universo virtual. Menciona Liliana Minardi Paesani (2014, p. 01):

A internacionalização da informação ancorou-se no movimento doutrinário que busca a proteção do interesse metaindividual e, no presente caso, o interesse coletivo ligado à informática e à telecomunicação. O setor de comunicação de massa é hoje uma das áreas em que mais se afirmam os novos direitos fundamentais do povo em sua essência comunitária.

Devendo cada caso em concreto ser ponderado de acordo com os interesses que estão em conflito, sendo analisado o potencial do conteúdo, mais precisamente, avaliando seu grau de lesividade em consonância com os princípios constitucionais da dignidade da pessoa humana e da solidariedade social (Martins, 2014).

Onde o princípio da dignidade da pessoa humana encontra-se como a base de todo os demais seguimentos, pois é o a máxima do Estado Democrático de Direito, resumindo-se a um valor inerente a todo indivíduo, resguardando que o ser humano nunca seja tratado como um objeto. Quanto ao princípio da solidariedade social, se caracteriza como um adágio importante para questões voltadas à rede mundial de computadores, uma vez que o coletivo e o individual devem colaborar um com o outro, para assim realizar seus objetivos, conforme expresso no artigo 3ㅇ da Constituição da República Federativa do Brasil:

Art. 3o Constituem objetivos fundamentais da República Federativa do Brasil:

I - construir uma sociedade livre, justa e solidária;

II - garantir o desenvolvimento nacional;

III - erradicar a pobreza e a marginalização e reduzir as desigualdades sociais e regionais;

IV - promover o bem de todos, sem preconceitos de origem, raça, sexo, cor, idade e quaisquer outras formas de discriminação.

Não olvidando, que objetivos como estes, impregnados na Constituição da República Federativa do Brasil, devem contribuir como uma forma de construir uma sociedade livre, justa e igualitária; no sentido de todos terem acesso à internet, à liberdade de informações e opiniões, desde que não transgrida os direitos de outrem, garantindo-se um desenvolvimento nacional; colaborando para que a internet esteja presente em todos os lares deste país, sendo utilizada para ampliar conhecimentos, auxiliando na erradicação de pobreza e marginalização, reduzindo desigualdades sociais e regionais; contribuindo para a promoção do bem de todos, sem preconceitos de raça, sexo, cor, idade e quaisquer outras formas de discriminação que possam ser articuladas no ambiente virtual. Assim dispõem Damásio de Jesus (2014, pag. 24):

Ao se tratar de políticas envolvendo o uso da internet no Brasil, deveremos considerar, sempre, o direito de inclusão digital ou de acesso a todos. Igualmente, a internet deve proporcionar acesso à informação, ao conhecimento e à participação na vida cultural e na condução de assuntos públicos. Logo, deverão ser gerados meios para a participação popular nos assuntos públicos, por meio da internet.

Posteriormente a estas discrições, é evidente que os princípios devem ser levados em consideração quando discutidas as disciplinas Direito e Internet, pois são eles que orientam o ordenamento jurídico de forma satisfatória. 
Sendo os princípios, verdades admitidas que fundam um sistema de conhecimento, por serem elas evidentes ou por terem sido comprovadas. Esclarecendo que são uma forma de enunciação normativa, que além de orientar a compreensão, condicionam o ordenamento jurídico, seja para a sua aplicação ou criação de novas normas (REALE, 2003).

Contudo, apesar de todos os benefícios que a internet ocasionou à população mundial, ela também veio acompanhada de maleficências, sejam elas crimes executados de forma virtual, preconceitos, bullying, ofensas à princípios e direitos fundamentais, excesso de informação, dependência de aparelhos eletrônicos, enfermidades, entre outros. Aponta André Francez (2013, pag. 07):

E nada mais oportuno. Como todos temos acompanhado, diariamente, a invenção da internet trouxe consigo muitas contradições. Se, por um lado aproxima pessoas distantes, por outro afasta pessoas próximas. Se, por um lado, possibilita o acesso a conteúdo e informação, por outro, facilita a violação de direitos pertencentes a criadores. Além disso, invade linhas tênues, como princípios constitucionais relacionados a intimidade, privacidade, imagem, direitos de autor e conexos, dentre outros, que muitas vezes podem ser expostos por seus titulares, sem respaldo do conhecimento sobre as normas que regem seus direitos. Esse cenário acaba gerando, muitas vezes, um ambiente propício para transgressão por parte daqueles que buscam vantagens econômicas através da violação do direito de terceiros.

Promovendo o surgimento de novos tipos de crimes e conceitos, que devem ser estudados e analisados com cautela, pois estão relacionados com a vida privada de cada indivíduo, seja na área do direito civil, do direito penal, do direito do consumidor, e outros ramos específicos do ordenamento jurídico; gerando e influenciando assuntos de extrema importância; como a propaganda eleitoral na internet, o comércio eletrônico, o marketing, a redução de custos na comunicação, e a tão revolucionária democracia eletrônica.

Alguns pontos importantes do uso da rede são protegidos atualmente pelo ordenamento jurídico, estando relacionados com as condutas ilícitas praticadas na internet, mais especificamente no Código Penal Brasileiro.

Todavia, abordando os direitos autorais, o artigo 184 do Código Penal protege o direito do autor e os que the são conexos, ou seja, são os direitos análogos do autor, que são aqueles que auxiliam na criação, produção e difusão da obra intelectual, sendo aplicados para os artistas, intérpretes, executantes, organismos de radio fusão e produtores de fonogramas no âmbito desses direitos (FRANCEZ, 2013).

Estando presente o famoso plágio, até mesmo na concorrência desleal, como uma falsa roupagem ou dissimulação, ilusão (MARTINS, 2014).

Quanto à privacidade, é um direito que também deve estar presente na internet, além de ter texto expresso na Constituição da República Federativa do Brasil, em seu artigo 50, inciso X, que resguarda a vida privada e a intimidade:

Artigo 50 - X: São invioláveis a intimidade, a vida privada, a honra e a imagem das pessoas, assegurado o direito a indenização pelo dano mate rial ou moral decorrente de sua violação.

Com relação a estes direitos, assim discorre Liliana Paesani Minardi (2014, pag. 34):

As especificações dos direitos e garantias expressos não excluem outros, decorrentes do regime e dos princípios adotados pela Constituição e de 
novos direitos da personalidade que virão a ser detectados com a evolução do pensamento jurídico, em sua constante luta para manter sob controle o avanço das técnicas, em razão das defesas e dos valores fundamentais da estrutura humana. $O$ direito à privacidade ou direito ao resguardo tem como fundamento a defesa da personalidade humana contra injunções ou intromissões alheias. Esse direito vem assumindo, aos poucos, maior relevo, com a expansão das novas técnicas de comunicação, que colocam o homem numa exposição permanente.

Existindo conflitos relacionados com a liberdade de imprensa e os interesses da personalidade, onde a internet se torna uma excelente ferramenta e de fácil difusão para qualquer meio de informação; aponta sobre os direitos da personalidade André Francez (2013, pag. 103):

São inatos, porque o ser humano já nasce com eles; são inseparáveis, tratando-se de uma emanação de sua personalidade, independentemente de serem reconhecidos pelo ordenamento jurídico. São vitalícios, porque possibilita seu uso, gozo e fruição durante toda a vida de seu criador e, após a sua morte, aos seus herdeiros, por certo período de tempo. São morais ou extrapatrimoniais, porque não têm um conteúdo econômico direto, embora deles possam advir reflexos patrimoniais a seu titular. Os direitos patrimoniais são relativamente indisponíveis e podem ser objeto de cessão, pelo tempo e modo estabelecidos, sendo vedada a transmissão dos direitos morais. São absolutos, porque não podem ser violados, pelo Estado ou por particulares. São autônomos, porque podem ser exercidos isoladamente. São direitos irrenunciáveis, imprescritíveis e intransmissíveis.

Porém, é possível que sejam impostos determinados limites à privacidade contra a própria vontade do indivíduo, em decorrência de sua posição na sociedade, sendo possível explanar se há o interesse público em divulgar a vida privada desta pessoa ou não (PAESANI, 2014).

É importante ressaltar, quando o interesse for coletivo, este predominará, não olvidando que se deve ser analisado cada caso em concreto, conforme salienta Liliana Minardi Paesani (2014, pag. 34):

Outros limites à privacidade podem ser impostos, quando atingem interesses coletivos diferentes do direito à informação e de maior relevância numa avaliação conjunta do interesse geral. A predominância do interesse coletivo sobre o particular requer, em cada caso, a verificação do alcance respectivo, a fim de não se sacrificar indevidamente a pessoa salvo quando a divulgação de notícias com finalidades científicas ou de polícia venham a sacrificar o interesse particular em prol da coletividade.

Conforme explanado neste tópico, a internet possui infinitas utilidades e facilidades, bem como inutilidades, gerando e contribuindo até mesmo para o aumento de determinadas doenças.

Sendo compreensível, portanto, que de acordo com a evolução social, as normas jurídicas devem se modificar, para, desta forma, estarem ajustadas com o entendimento dos indivíduos. Por conseguinte, com o uso diário da internet, todos devem estar atentos aos direitos e obrigações que dela decorrem. Além de se tomar o devido zelo com futuras mazelas que possam 
ser sofridas, caso os indivíduos não dominem corretamente esta excelente e revolucionária ferramenta.

\section{CONCLUSÃO}

Apesar do Brasil possuir em seu ordenamento jurídico determinados dispositivos que abarcam casos específicos envolvendo a internet, ainda carece de leis específicas e claras que orientem o uso da rede mundial de computadores. Deste modo, os legisladores precisam dar mais atenção às normas que refletem o uso da internet no país, regulamentando as diversas conjunturas que podem advir durante a utilização da rede pelos usuários, pois a sociedade convive em uma era de globalização e conexão, onde o simples despertar e comunicar envolve o uso desta insigne ferramenta.

Verifica-se, que a internet está sendo utilizada como um veículo para a realização de condutas ilícitas, como um instrumento para efetivá-las. Sendo abstruso prever qual bem jurídico será lesionado na vasta rede, onde novas ilicitudes surgem diariamente; tornando-se imprescindível sua proteção de acordo com sua evolução diária, a qual ocorre com o surgimento de novos aplicativos e tecnologias.

\section{REFERÊNCIAS}

BRASIL. Constituição (1988). Constituição da república federativa do brasil. Brasília: Senado Federal, 1988.

BRASIL. Código de Processo penal. Decreto-Lei no 3.689, de 3 de outubro de 1941. Disponível em http://www.planalto.gov.br/ccivil_03/decreto-lei/Del3689.htm. Acesso em 01 ago.2017.

CASAGRANDE, Álvaro Augusto Portella Trento Colle. A internet e o direito. Dissertação apresentada no curso de pós-graduação em direito da universidade federal de Santa Catarina com requisito à obtenção do título de mestre em ciências humanas - especialidade direito, 1996.

FRANCEZ, André. Direito do entretenimento na internet. 1 ed. São Paulo: Saraiva, 2013.

JESUS, Damásio de. Marco civil da internet : comentários à Lei n. 12.965, de 23 de abril de 2014, 1 ed. São Paulo: Saraiva, 2014.

Martins, Guilherme (Coord.). Direito privado e internet: Atualizado pela Lei $n^{\circ}$ 12.965/2014: Atlas, 2014.

OLIVEIRA, Adriana.; ORTEGA, Jakeline.; MOLOGNI, Michele. Normas e Padrões para trabalhos acadêmicos e científico da Unoeste, 3. Ed. Presidente Prudente-SP, 2015.

Paesani, Liliana Minardi. Direito e internet: Liberdade de Informação, Privacidade e Responsabilidade Civil. 7. ed. São Paulo: Atlas, 2014.

REALE, Miguel. Lições preliminares de direito. 27ạ ed. São Paulo: Saraiva, 2003. 